ARTIGO

DE REVISÃO

\title{
Exercício e sono
}

\author{
Paulo José Forcina Martins, Marco Túlio de Mello e Sergio Tufik \\ Departamento de Psicobiologia da Universidade Federal de São Paulo \\ Instituto do Sono - Unifesp
}

\section{INTRODUÇÃOO}

O exercício tornou-se uma unanimidade na promoção da saúde e melhora da qualidade de vida, diminuindo os riscos de desenvolvimento de doenças crônicas e atuando como fator-chave para aumentar a longevidade. Em contrapartida, a perturbação do ciclo sono-vigília resulta em significativos danos à saúde e ao bem-estar, representando nos casos mais graves risco de morte ${ }^{1-3}$. Em vista da suas consequiências e incidência, os distúrbios do ciclo sonovigília são considerados um problema de saúde pública ${ }^{4,5}$.

Investigações sobre os efeitos do exercício físico no padrão de sono tiveram inicio há mais de 30 anos. Heinzelmann e Bagley ${ }^{6}$ estudaram a capacidade de um programa de atividade física na promoção de comportamentos saudáveis. O treinamento teve duração de 18 meses, dividida em três sessões semanais de uma hora; os participantes relataram menor necessidade de sono, assim como um sono mais relaxado e restaurador ${ }^{6}$.

As causas mais comuns de prejuízo do sono são a restrição e a sua fragmentação. A restrição do sono pode ser resultado da demanda de trabalho ou escola, responsabilidade familiar, uso de medicamentos, fatores pessoais e estilos de vida. A fragmentação resulta em um sono de quantidade e qualidade inadequadas, sendo conseqüência de condições médicas e/ou fatores ambientais que o interrompem $^{2}$.

Como conseqüências da alteração do padrão de sono podem ocorrer reduções da eficiência do processamento cognitivo, do tempo de reação e responsividade atencional; além de déficit de memória, aumento da irritabilidade, alterações metabólicas, endócrinas e quadros hipertensi$\operatorname{vos}^{7-13}$.

Recebido em: 21/12/2000.

Aceito em: 6/1/2001.

Endereço para correspondência:

Paulo José Forcina Martins

Rua Marselhesa, 535

04020-060 - São Paulo, SP

E-mail: pmartins@psicobio.epm.br
Atualmente, os exercícios são reconhecidos pela American Sleep Disorders Association como uma intervenção não-farmacológica para a melhora do padrão de sono ${ }^{14}$. Porém, efetivamente, a prescrição de exercícios físicos com essa finalidade ainda é reduzida, possivelmente como um reflexo da falta de conhecimento por parte de professores e médicos dos benefícios dos exercícios nessa área.

O objetivo desta revisão é discutir os principais aspectos do ciclo sono-vigília, enfatizando as características do padrão de sono e as influências do exercício no ciclo sonovigília. Desta forma, pontuamos fatores como: horário, aptidão física, relação entre a duração e intensidade do exercício que se relacionam com as teorias pelas quais se tenta justificar os efeitos do exercício sobre o sono. Por último, sugerimos alguns métodos que possam auxiliar, em especial os atletas, a minimizar os problemas de sono que podem prejudicar tanto as atividades diárias como os treinamentos.

\section{SONO}

Apesar do interesse sobre o sono existir desde aproximadamente 1.000 a.C., ainda hoje não se conhece a função deste fenômeno. Apesar das inúmeras teorias propostas, ainda não existe uma que inspire confiança em que a essência do sono tenha sido totalmente capturada ${ }^{15-17}$.

Junto aos estudos de sono em humanos e animais, vários conceitos de sono foram elaborados com base em aspectos funcionais e comportamentais deste fenômeno. Entre alguns destes conceitos, Buela ${ }^{18}$ definiu o sono como um estado funcional, reversível e cíclico, com algumas manifestações comportamentais características, como uma imobilidade relativa e o aumento do limiar de resposta aos estímulos externos. Em termos orgânicos ocorrem variações dos parâmetros biológicos, acompanhados por uma modificação da atividade mental, que correspondem ao comportamento de dormir.

As pesquisas científicas modernas sobre o padrão de sono e os mecanismos envolvidos na indução e manutenção deste fenômeno iniciaram-se no século XIX, com o desenvolvimento de ferramentas eletrofisiológicas necessárias ao es- 
tudo de biopotenciais de pequena amplitude. Em 1875, Caton registrou a atividade elétrica espontânea de cérebros de coelhos, gatos e macacos. Entretanto, os biopotenciais cerebrais de humanos foram registrados somente em 1929 por Berger, que estudou a atividade elétrica do córtex exposto de pacientes com tumor cerebral. O resultado deste registro foi denominado eletroencefalograma ou $\mathrm{EEG}^{19}$.

Em 1937, Harvy e Loomis realizaram o registro de EEG durante a noite toda em humanos. Eles demonstraram que o sono consiste de alternância de estágios que poderiam ser diferenciados pelo seu padrão de EEG, e que estes estágios aparecem espontaneamente sob orientação de algum mecanismo regulatório do sistema nervoso central. Estes autores criaram o primeiro sistema de classificação dos estágios de sono e também descreveram várias características importantes do EEG que são usadas no atual sistema de classificação dos estágios do sono ${ }^{20}$. Atualmente, estes estágios do sono identificados por Loomis et al. são chamados de estágios 1, 2, 3 e 4 do sono ${ }^{21}$.

Somente em 1953 foi identificado o último dos estágios de sono que atualmente se conhecem. Aserinsky e Kleitman observaram um novo padrão de EEG de sono consistindo de baixa voltagem e atividade rápida do EEG associada aos movimentos rápidos dos olhos. Estes autores ainda reconheceram que este fenômeno estava associado com os sonhos. Este estágio foi então chamado de sono REM ( $r a-$ pid eye moviment), que se alterna regularmente com os estágios descritos por Loomis et al., que por exclusão foram coletivamente chamados de sono não-REM (NREM) ${ }^{14,20}$.

\section{Classificação dos estágios de sono}

O sistema de classificação dos estágios do sono atualmente mais aceito foi proposto por Rechtschaffen e Ka$\mathrm{les}^{22}$. Uma premissa importante deste sistema de classificação é que o sono REM, sono NREM e a vigília são estados da consciência fundamentalmente diferentes, determinados por variáveis eletrográficas e fisiológicas. Nem o sono nem a vigília são considerados processos unitários e as subdivisões são quase sem limites dentro de qualquer estágio $^{22}$.

Os parâmetros eletrográficos essenciais usados para a determinação dos estágios do sono são o eletroencefalograma (EEG), eletrooculograma (EOG) e o eletromiograma (EMG). A classificação dos estágios de sono é realizada em intervalos de registro entre 20 e 60 segundos, denominados de época ${ }^{22}$. As épocas podem ser classificadas da seguinte forma:

- Vigília

- Sono não-REM:

- Estágio 1 do sono

- Estágio 2 do sono
- Estágio 3 do sono

- Estágio 4 do sono

- Sono REM

A vigília tranqüila é caracterizada por um período de atividade elétrica $\alpha$ ( 8 a 13Hz) e/ou uma baixa voltagem, apresentando o EEG deste estágio uma freqüência mista; acompanhado por alta atividade eletromiográfica e freqüentes movimentos oculares voluntários ${ }^{23}$.

Progressivamente o estágio 1 do sono não-REM (NREM), também conhecido como "estágio de transição" ou "meio sono", se estabelece, durando em média de um a sete minutos ${ }^{14,19}$. O estágio 1 do sono NREM é caracterizado por um EEG de baixa amplitude, freqüência mista entre a faixa $\alpha$ e $\sigma(2 \mathrm{a} 7 \mathrm{~Hz})$. A atividade do EMG é normalmente mais alta do que nos outros estágios do sono, mas a amplitude pode variar muito. O EOG mostra, às vezes, movimentos oculares lentos. Este estágio representa até 5\% do tempo total de sono ${ }^{22,24}$.

O estágio 2 do sono NREM é reconhecido pela atividade $\sigma$ de fundo e episódios de fusos de sono e complexos-K. Os fusos de sono são ondas de curta duração (12 a 14Hz) que aumentam e diminuem em amplitude para produzir uma característica de fuso. O complexo-K é uma onda com um componente negativo de alta amplitude seguido imediatamente por um componente positivo mais lento. Às vezes, os complexos-K estão relacionados a estímulos auditivos, mas outras vezes parecem ocorrer espontaneamente. Este estágio normalmente constitui a maior proporção do sono nos humanos adultos, 45 a $55 \%$ do tempo total de sono $^{19,22}$.

O estágio 3 do sono NREM é classificado quando ondas lentas ou ondas $\delta(\leq 2 \mathrm{~Hz})$ e alta amplitude, maior que $75 \mu \mathrm{V}$ (medido do valor mais baixo ao mais alto da onda - peak to peak) aparecem em 20 a $50 \%$ da época do registro. O EMG normalmente demonstra baixa atividade e os movimentos oculares estão ausentes, mas estes critérios não são relevantes para a classificação ${ }^{22}$.

O estágio 4 do sono NREM é semelhante quanto ao EEG, EMG e EOG do estágio anterior; entretanto, o estágio 4 caracteriza-se pela presença de ondas $\delta$ em mais de $50 \%$ da época ${ }^{22}$.

Os estágios 3 e 4 do sono NREM são freqüentemente combinados, visto que diferem somente na proporção de ondas lentas no EEG, e são coletivamente denominados de sono de ondas lentas ou sono delta. Durante a parte inicial da noite o estágio 3 normalmente aparece como um estágio de transição entre o estágio 2 e 4 . Na maioria dos adultos sob condição normal, o estágio 4 do sono NREM é observado principalmente no primeiro terço da noite, enquanto a maioria do sono NREM no final da noite é o estágio 3 do sono NREM ${ }^{19}$. O estágio 3 do sono NREM tipicamente cons- 
titui até $8 \%$ do tempo total de sono; e o estágio 4 até $15 \%$ do tempo total de sono ${ }^{24}$.

O sono NREM é fisiologicamente tranqüilo e estável comparado à vigília e ao sono REM. As frequiências cardíaca e respiratória tendem a ser baixas e mais regulares; os músculos estão relaxados, embora o tônus muscular esteja presente em toda a extensão do estágio NREM. Os movimentos oculares são raros, exceto os movimentos oculares lentos do início do sono. Quando o sujeito é acordado durante este estágio, tipicamente relata pensamentos fragmentados, cenas ou imagens vagas, ou sem atividade mental ${ }^{19}$.

Em 1953, Kleitman e Aserinsky causaram uma verdadeira revolução no estudo do sono. Com o objetivo de observar se os movimentos oculares lentos que ocorrem no início poderiam reaparecer em outros períodos do sono, estes pesquisadores avaliaram o sono de crianças, que também dormem durante o dia, e observaram inicialmente que os movimentos oculares lentos do início do sono eram substituídos por movimentos oculares rápidos, semelhantes aos movimentos oculares da vigília, apesar dos sujeitos estarem dormindo ${ }^{14}$. De posse destes achados, Dement e Kleitman realizaram um estudo em que os sujeitos eram acordados durante os movimentos oculares rápidos e em seguida questionavam-se se estavam sonhando. Concluíram que, apesar dos movimentos oculares semelhantes aos da vigília, os sujeitos estavam dormindo e sonhando. Em vista deste paradoxo, alguns autores preferem classificar este estágio de sono como "sono dos sonhos", "sono paradoxal", ou ainda "sono ativo"14.

O sono dos movimentos oculares rápidos é caracterizado por EEG de atividade de freqüência mista, baixa voltagem, semelhante ao estágio 1 do sono NREM. O sono REM é acompanhado por uma série de alterações fisiológicas. A atividade muscular, normalmente registrada nos músculos submentonianos, atinge os níveis mais baixos durante o sono REM. Os eventos fásicos do sono REM são observados por um alto grau de ativação autonômica, incluindo freqüências cardíaca e respiratória elevadas e irregulares e elevações da pressão arterial ${ }^{22}$.

Outras alterações fisiológicas chamam a atenção para o REM. Neste estágio do sono o fluxo sanguíneo cerebral atinge valores mais altos do que em qualquer outro estágio. Observa-se, ainda, aumento na temperatura cerebral e maior consumo de oxigênio durante esta fase. $\mathrm{O}$ sistema de termorregulação é suspenso, pois os mecanismos de transpiração, tremor, vasodilatação, vasoconstrição e taquipnéia térmica estão relativamente inativos ou ausentes. A atonia muscular é mais intensa nos músculos do pescoço, mas afeta todos os principais grupos musculares. Abalos musculares vistos no sono REM podem ser relacionados às imagens mentais dos sonhos ${ }^{23}$.
Quando os sujeitos adultos são acordados durante o sono REM, são capazes de recordar o conteúdo dos sonhos em mais de $70 \%$ dos eventos. Uma outra característica fisiológica em homens é a ocorrência da tumescência peniana durante os episódios de sono REM sustentados ${ }^{19}$. Normalmente, o sono REM constitui cerca de 20 a $25 \%$ do tempo total de sono nos indivíduos adultos ${ }^{24}$.

\section{Fatores que regulam o ciclo sono-vigília}

Talvez não nos damos conta, mas aproximadamente 1/3 de nossas vidas é dedicado a um período de relativa inatividade ao qual é associado um padrão eletroencefalográfico e comportamental que caracteriza o sono ${ }^{25}$. O sono, sem dúvida, é um estado vital e complexo caracterizado por processos ativos e altamente organizados ${ }^{26}$.

Para a organização dos períodos de vigília e de sono, três processos básicos estão envolvidos. 1) processos circadianos, que, na sua maioria, se não em todos os ritmos dos mamíferos, é regulado pelo núcleo supraquiasmático do hipotálamo anterior, resultando na alternância de alta e baixa propensão ao sono dentro do período de 24 horas do dia; 2) processos homeostáticos, que são determinados pela vigília anterior influenciando a intensidade e, em menor extensão, a quantidade de sono. Sob condição normal, modulam a propensão circadiana ao sono; 3 ) processos $\mathrm{ul}$ tradianos, os quais definem alternância entre o sono NREM e sono REM dentro de um episódio de sono. Embora os processos homeostáticos e circadianos estejam separados, sua interação é que determina a distribuição temporal e duração do sono e vigília. Conseqüentemente, alterações na ritmicidade circadiana são acompanhadas por alterações no sono ${ }^{26,27}$

Regulação ultradiana: no ser humano, assim como em outros mamíferos, podemos observar uma alternância entre períodos de sono REM e de sono NREM durante os episódios de sono. O conhecimento sobre os mecanismos organizadores do "ciclo de sono" ainda é controverso. Postulou-se que os ciclos de sono ocorreriam sob coordenação de um oscilador endógeno, mas estudos recentes sugerem que não há necessidade de um oscilador para que ocorra esta variação entre estes dois estágios básicos do sono ${ }^{27}$. No estudo de Gronfier et al. ${ }^{28}$, buscou-se verificar a ligação entre o padrão oscilatório das ondas delta, a ativação do sistema adrenocorticotrópico e o sistema nervoso autônomo durante o sono; concluiu-se que o aumento na secreção de cortisol e no tônus simpático descreve oscilações intimamente ligadas à profundidade e extensão do sono, de maneira a coordenar harmoniosamente os processos ultradianos para assegurar um sono de boa qualidade.

Regulação homeostática: a alta intensidade de ondas lentas no sono NREM parece ser um bom indicador fisioló- 
gico da homeostase do sono ${ }^{29}$. Em 1937, Loomis et al. estudaram a relação entre a responsividade a estímulos externos e o EEG registrado durante o sono. Demonstraram que a intensidade de sono é refletida pela predominância de ondas lentas no EEG de sono. Tal afirmação foi comprovada com a demonstração de que a responsividade a estímulos diminui quando o EEG de ondas lentas torna-se mais predominante. Em condições normais, pode-se considerar como um indicador da "profundidade do sono" ou "intensidade do sono" 30 .

Tanto o limiar de despertar quanto a predominância de sono de ondas lentas no EEG são altos na parte inicial do sono e progressivamente diminuem com o transcorrer do episódio de sono. É natural assumir que a necessidade do sono é alta durante a parte inicial do sono e gradualmente diminui com a progressão do sono ${ }^{30}$.

Existem evidências fortes de que o nível de atividade de ondas lentas no EEG é determinado pela duração da vigília anterior e não por algum fator específico. Os estudos de cochilos em vários períodos do dia demonstraram que a propensão da atividade de ondas lentas aumenta gradualmente no decorrer do período habitual de vigília. Além disso, existe uma variação diurna sistemática na propensão dos episódios de sono REM que se assemelha à variação da temperatura retal ${ }^{31}$.

Ainda não está claro se a atividade de ondas lentas é determinada por algum aspecto específico da vigília ou somente pela duração deste estado. Existem evidências de que o metabolismo cerebral pode ser um importante fator, pois quando se comparam três horas de vigília forçada ou espontânea com três horas de sono, observa-se um aumento na expressão de RNA-mensageiro mitocondrial durante o período de vigília ${ }^{32}$. Isto pode representar uma resposta regulatória dos neurônios ou da glia, como adaptação ao aumento na demanda metabólica da vigília em relação ao sono $^{32}$.

As características do sono são de interesse tanto para a compreensão dos mecanismos envolvidos na expressão deste comportamento quanto para patologias inerentes ao sono. Estudos em camundongos revelaram que diferenças na duração e início de sono, período do principal repouso e fragmentação do sono de ondas lentas, encontram-se sob controle genético. Tais estudos sugerem que os fatores responsáveis pelos mecanismos de regulação homeostática do sono são controlados por um número reduzido de genes ${ }^{33}$.

Regulação circadiana: a organização temporal dos comportamentos de repouso e atividade nos mamíferos, sem dúvida, é a mais evidente manifestação da adaptação aos estímulos ambientais. A alternância constante entre claro e escuro ambiental leva a dois padrões de comportamentos nos mamíferos. Mamíferos que utilizam a olfação e a audi- ção como sentidos principais para a percepção do ambiente, tipicamente, dormem durante o dia e são ativos durante a noite, apresentando, portanto, padrão noturno. De modo oposto, mamíferos que utilizam a visão como sentido primário permanecem acordados durante o dia e dormem durante a noite, em um padrão diurno ${ }^{34}$.

Pode-se imaginar que os períodos de sono e vigília, assim como outros ritmos biológicos, seriam simplesmente uma resposta aos estímulos ambientais. Entretanto, isto não é verdade, visto que estudos em animais e em humanos colocados em isolamento temporal, ou seja, em um ambiente sem indicadores do tempo, demonstraram que o ciclo de sono-vigília persiste no que é chamado de ritmo em livre-curso. Isto é, o ritmo persiste, porém com um período que difere de 24 horas. A manutenção do ritmo em livrecurso é, portanto, atribuída a um relógio intrínseco ou marca-passo ${ }^{34}$.

A estrutura neuronal responsável pela organização temporal de vários ritmos biológicos que incluem: ciclo sonovigília, atividade locomotora, de roer e geral, temperatura corporal, comportamento de consumo de água e alimento, o ritmo de secreção hormonal e de peptídeos, está localizada no núcleo supraquiasmático do hipotálamo. O controle destes ritmos por este núcleo hipotalâmico pode ser comprovado por dois tipos de estudos. Estudos de lesão no núcleo supraquiasmático, que levaram a uma ausência de ritmicidade na expressão destes vários ritmos biológicos, e estudos de transplante de células do núcleo supraquiasmático, que foram capazes de restabelecer a ritmicidade de alguns destes ritmos. Contudo, ainda não está claro qual é o mecanismo pelo qual este núcleo realiza a organização temporal destes ritmos ${ }^{35}$.

No homem, portanto, existem dois estados claramente diferenciados: a vigília e o sono. A magnitude e a distribuição destes estados ao longo das 24 horas do dia são muito variáveis, dependendo fundamentalmente da idade e do padrão de sono ${ }^{36}$.

\section{EXERCÍCIO E SONO}

Inicialmente, a falta de conhecimento sobre a função primordial do sono levou à utilização do exercício físico como um paradigma nas investigações de teorias que explicassem a importância do sono ${ }^{17,37,38}$.

Assim, os modelos teóricos que buscam explicar os efeitos do exercício sobre o sono estão associadas às hipóteses termorregulatória, da conservação de energia e da restauração corporal.

Evidências dos efeitos do exercício sobre o sono a partir dos mecanismos termorregulatórios foram inicialmente propostos por Horne e Moore. Estes autores verificaram que após exercício com aquecimento por uso de roupas 
extras ocorria um aumento no sono de ondas lentas, o que não aconteceu em exercícios com esfriamento abrupto após o término da sessão ${ }^{39}$.

A hipótese termorregulatória apóia-se na evidência de que o início do sono é disparado pela redução da temperatura corporal que ocorre circadianamente no início da noi$t^{40}$. Alguns estudos descrevem a função crucial do hipotálamo na regulação da temperatura corporal e na indução do sono ${ }^{41}$.

Portanto, o exercício, ao aumentar a temperatura corporal, criaria uma condição capaz de facilitar "o disparo" do início do sono, por ativar os processos de dissipação de calor controlados pelo hipotálamo, assim como os mecanismos indutores do sono dessa mesma região ${ }^{37}$. Tanto a teoria da conservação de energia como a da restauração corporal apóiam-se nos mecanismos homeostáticos reguladores do sono ${ }^{27}$, visto que ambas as teorias afirmam que a duração total do episódio de sono, assim como a quantidade de sono de ondas lentas, aumenta em função do aumento do gasto energético ${ }^{37}$.

A redução do metabolismo durante o sono e a sensação de fadiga descrita por sujeitos privados de sono reforçam a hipótese de que o sono tenha uma função restauradora ${ }^{11,17}$. 42-44.

A teoria restauradora ou compensatória prediz que a condição para a atividade anabólica durante o sono é favorecida após alta atividade catabólica durante a vigília ${ }^{37}$. Dessa forma, o exercício poderia facilitar o sono por reduzir as reservas energéticas corporais, o que aumentaria a necessidade de sono, principalmente do sono de ondas len$\operatorname{tas}^{45}$.

A teoria da conservação de energia também é baseada na redução da taxa metabólica que é observada durante os períodos de sono. Entretanto, uma versão afirma que o sono reduz o metabolismo abaixo do gasto durante a vigília, e outra, que o sono limita o gasto energético, sendo que ambas permitiriam um balanço energético positivo ${ }^{37,46}$. O exercício, portanto, facilitaria o sono por aumentar o gasto energético durante a vigília e isto aumentaria a necessidade de sono, de forma que se possa alcançar um balanço energético positivo e se restabeleça a condição adequada para um novo episódio de vigília ${ }^{47}$.

\section{Efeitos do exercício sobre o ciclo sono-vigília}

Apesar de os estudos sobre a influência do exercício no sono não serem unânimes quanto às alterações do padrão de sono, o aumento no sono de ondas lentas é, na maioria dos estudos, a principal observação.

Em 1966, Baekeland e Lasky ${ }^{48}$ submeteram dez jovens do sexo masculino a um registro polissonográfico após uma sessão habitual de exercícios durante a tarde. Puderam ob- servar uma relação positiva entre a quantidade de sono de ondas lentas, estágios 3 e 4 do sono, e a quantidade de exercícios realizados durante o dia.

Especulações de que o efeito do exercício sobre o sono poderia decorrer da privação de sono ocorrida durante a atividade levaram Hobson ${ }^{47}$ a comparar o efeito da privação de sono com o exercício moderado $(0,53$ a $1,13 \mathrm{~km} / \mathrm{h})$ em gatos. Quatro gatos foram submetidos à privação de sono e exercícios em dias alternados. Realizou-se um registro de EEG, EOG e resposta ao condicionamento operante durante todo o período subseqüente, exceto entre duas e quatro horas da tarde, período em que se realizava o exercício. Observou-se uma redução no número de respostas ao condicionamento operante, acompanhada de aumento no número de episódios e duração do sono de ondas lentas. Por outro lado, a privação de sono não produziu nenhuma alteração significativa nos parâmetros estudados ${ }^{47}$.

Estudos mais recentes têm confirmado a observação do aumento do sono de ondas lentas em conseqüência do exercício físico. Youngstedt et al. ${ }^{49}$ verificaram os efeitos do exercício sobre o sono após o consumo de altas doses de cafeína durante o dia. Como nos estudos anteriores, observou-se um aumento no sono de ondas lentas após o exercício (sem cafeína); entretanto, este aumento foi um terço menor após o consumo de cafeína. Isto sugere uma participação do sistema de neurotransmissão adenosinérgico no aumento no sono de ondas lentas após o exercício.

As conseqüências do exercício sobre o sono REM foram priorizadas por Matsumoto et al. ${ }^{50}$. Após quatro horas de exercícios na esteira, ratos apresentaram um aumento da latência para o sono REM. Esta latência, entretanto, foi revertida com a administração de L-dopa, indicando a ocorrência de uma redução das monoaminas após o exercício extenuante, que por conseguinte leva ao aumento da latência de sono REM. Outros trabalhos acabaram por constatar que os exercícios podem aumentar a latência para o sono REM e/ou diminuir o tempo deste período de sono ${ }^{39,47-49}$. Em um estudo de metanálise realizado por Youngstedt et $a l .{ }^{51}$, verificou-se que o exercício aumenta a latência para o sono REM e/ou diminui o tempo desse estágio de sono em aproximadamente seis minutos e 11,6 minutos, respectivamente. Estas alterações podem ser utilizadas como um índice de estresse induzido pelo exercício ${ }^{52}$.

Em alguns estudos o exercício mostrou-se capaz de reduzir a latência para o início do sono ou pelo menos não alterá-la ${ }^{47,50,53}$. Recentemente, os exercícios foram usados para reverter os efeitos da cafeína, uma droga que mimetiza as alterações no padrão de sono causadas pela insônia, principalmente latência de sono elevada. Pode-se observar que o exercício não foi capaz de reduzir a latência aumentada pela ingestão de cafeína ${ }^{49}$. Segundo os autores, a falha 
em reduzir a latência para o início do sono pode ser explicada pelo fato de o exercício não ter efeito maior no sono alterado do que o observado no sono normal.

Entre outras razões possíveis para explicar a falha dos estudos em demonstrar que o exercício pode reduzir a latência para sono estaria uma subestimação dos efeitos do exercício, visto que as amostras estudadas são, em grande parte, de bons dormidores, o que deixa pouco espaço para melhorar o sono (ceiling effect) $)^{51,52}$.

O aumento no tempo total de sono também pode estar associado aos exercícios físicos de maneira a reforçar a necessidade de mais sono para restabelecer a homeostase perturbada pelo exercício. Este efeito sobre o sono parece ser observado tanto para exercícios agudos, em que não há adaptação à sua duração $0^{51,53}$, quanto de forma crônica, visto que indivíduos treinados apresentam maior tempo total de sono do que sedentários, mesmo quando fora de treinamento ${ }^{45,52}$.

Em vários estudos foi observado que o horário de realização dos exercícios pode representar um importante fator nas respostas do EEG de sono. A falta de padronização no exercício aplicado e o período do dia em que se realizava a atividade levaram Horne e Porter ${ }^{54}$ a estudarem a relação entre a fadiga produzida pelo exercício e o padrão de sono de oito homens saudáveis. O exercício consistia de $85 \mathrm{mi}-$ nutos de exercícios com 15 minutos de descanso na metade do período. O registro polissonográfico foi realizado durante duas noites consecutivas; sem exercícios, após exercícios pela manhã e após exercícios à tarde. Os resultados mostraram que após o exercício à tarde houve um aumento significativo do estágio 3 do sono NREM na primeira metade do registro. Além disso, parece que houve um aumento na latência para o sono REM, mas, assim como os outros parâmetros, não foi significativo ${ }^{54}$.

Vários outros estudos mostraram que exercícios próximos ao horário de dormir podem levar a um aumento na latência para o sono e um aumento no sono de ondas lentas, enquanto exercícios realizados pela manhã não o fazem $^{48,49}$. Sasazawa et al. ${ }^{55}$ estudaram os efeitos de aulas de caratê no padrão de sono de cinco jovens (19 a 20 anos) que praticavam o exercício regularmente. Os exercícios foram realizados entre 17:00 e 20:00 horas, três horas antes do horário habitual de dormir. Houve uma redução na latência para o sono nos dias em que se realizou o exercício em comparação com os dias sem exercícios, provavelmente como conseqüência de uma adaptação ao horário do exercício. A realização de exercícios vigorosos durante a noite também foi verifica por Youngstedt et al. ${ }^{56}$. Os participantes eram 16 ciclistas altamente treinados, com idade média de 27,3 anos, que terminaram uma sessão de três horas de exercícios, entre 65 e $75 \%$ da freqüência cardíaca de reserva, 30 minutos antes da hora de dormir. Os resultados mostraram que os exercícios realizados tarde da noite não perturbaram o sono de indivíduos treinados.

O exercício também pode atuar no ciclo sono-vigília através do seu efeito sincronizador indireto do relógio biológico, ou seja, pode levar a um sono de melhor qualidade sincronizando os horários de sono ao melhor momento do $\operatorname{dia}^{57-59}$.

Um grupo de 16 homens, entre 19 e 41 anos de idade, realizou 15 minutos de exercícios a cada hora, durante oito horas. Tanto o ritmo da temperatura corporal quanto do hormônio melatonina, dois marcadores dos ritmos circadianos, ajustaram-se ao horário de sono durante o dia. Estes sujeitos relataram período maior de sono, menos fadiga, mais vigor e menos distúrbios do humor ${ }^{60}$. A utilização de três horas de exercícios contínuos, durante a noite, mostrou um atraso entre uma ou duas horas na secreção de melatonina e tirotropina ${ }^{61}$. O estudo realizado por Buxton et al. ${ }^{62}$ mostrou que exercícios contínuos de uma hora eram suficientes para produzir os efeitos sincronizadores em humanos.

\section{Efeitos da relação duração e intensidade sobre o sono}

As características do exercício e a aptidão física do indivíduo são variáveis importantes para as respostas no padrão de sono. A avaliação do padrão de sono após exercícios com várias cargas de trabalho foi realizada por Shapiro et $a l .{ }^{63}$. O protocolo experimental consistia de exercícios a $50 \%$ do consumo máximo de oxigênio por duas, quatro ou seis horas em cicloergômetro; duas sessões de 80 minutos de exercícios a $75 \%$ do consumo máximo de oxigênio em cicloergômetro, separados por 60 minutos de recuperação. Já no último experimento, os indivíduos realizaram três horas de exercício em step a $50 \%$ do consumo máximo de oxigênio em temperatura ambiente de $33^{\circ} \mathrm{C}$. Houve uma relação entre o aumento da sobrecarga do exercício e o aumento no sono de ondas lentas, aparentemente devido ao estresse fisiológico do exercício e ao aquecimento corporal. A redução progressiva do sono REM foi observada em todos os experimentos; entretanto, o estágio 2 do sono NREM se alterou somente após o quinto experimento, sugerindo que tal alteração foi decorrente de uma maior fadiga ${ }^{63}$.

A comparação do sono de oito atletas de ultratriátlon mostrou que após a realização de provas de 15 e 42,2km de corrida não houve diferença do padrão de sono sem exercícios. Entretanto, após a prova de ultratriátlon houve aumento na latência do sono REM (90 vs. 186 minutos), redução no sono REM em aproximadamente 45 minutos e aumento de $40 \%$ no tempo acordado após o início do sono em relação à noite sem exercícios. Estas alterações foram 
atribuídas ao fato de que estes atletas estavam adaptados à carga de trabalho de provas de 15 e $42,2 \mathrm{~km}$, e que a prova de ultratriátlon representou um alto nível de estresse para estes atletas ${ }^{53}$.

A duração dos exercícios foi um dos principais fatores descritos por Youngstedt et al. ${ }^{51}$ para alterar o padrão de sono. Exercícios com duração maior do que uma hora levaram a uma redução significativa no sono REM, o qual não foi influenciado por outros fatores. O tempo total de sono também mostrou uma relação linear com a duração do exercício, sendo que os maiores aumentos no tempo total de sono foram observados após exercícios de maiores durações.

Segundo Driver e Taylor ${ }^{52}$, a influência da intensidade do exercício no padrão de sono é contraditória. Enquanto alguns trabalhos mostram aumento no sono de ondas lentas após exercícios de 50 a $80 \%$ do $\mathrm{V}_{2}$ máx., outros estudos descrevem que exercícios com duração de uma hora variando a intensidade, próximo à intensidade máxima ou mesmo dentro da zona usual de treinamento, não produziram efeitos no sono de ondas lentas.

\section{CONSIDERAÇÕES FINAIS}

Observa-se, portanto, que os exercícios podem auxiliar no tratamento e prevenção de alguns distúrbios do ciclo sono-vigíliaa ${ }^{64,65}$, seja diretamente, por diminuir a fragmentação do sono, provocar aumento no sono de ondas lentas e diminuição da latência para o de sono, ou indiretamente através do controle de peso e aquisição de hábitos saudáveis.

Um levantamento epidemiológico da prática de atividade física na cidade de São Paulo mostrou que as queixas de insônia e de sonolência excessiva, entre os entrevistados que realizam atividade física regularmente, eram de apenas $27,1 \%$ e $28,9 \%$, respectivamente, enquanto entre os não praticantes foram de $72,9 \%$ e $71,1 \%$, respectivamente ${ }^{66}$.

Sabe-se que um fator importante para o ganho de desempenho é um período de recuperação adequado e este período de recuperação sem dúvida alguma inclui o sono. A importância do sono na recuperação entre as sessões de treinamento torna-se mais evidente, em vista da associação entre a secreção de hormônio de crescimento $(\mathrm{GH})$ e o sono de ondas lentas, podendo-se inferir a importância de um sono adequado para a restauração corporal.

A relação entre GH e sono de ondas lentas já está muito bem estabelecida, sendo que cerca de $50-70 \%$ da secreção do hormônio ocorre durante a parte inicial do sono ${ }^{67}$. O aumento na secreção deste hormônio levou à idéia de que o sono de ondas lentas poderia estar relacionado com a restauração dos estoques energéticos e ressíntese protéi-

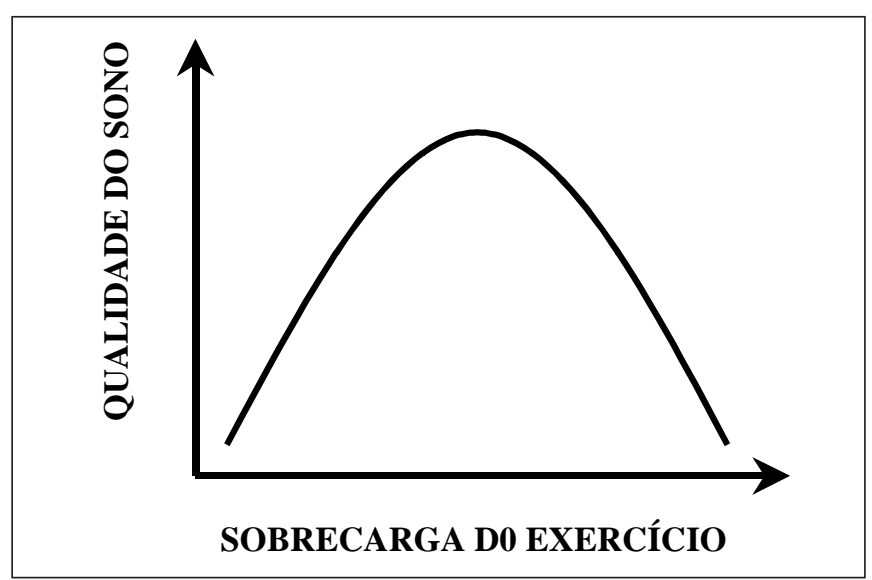

Fig. 1 - Relação entre a sobrecarga do exercício e qualidade do sono durante a noite seguinte de sono

ca $^{17,68}$, sendo que esta função ainda é contestada ${ }^{69}$. Por outro lado, o perfil noturno de GH mostrou-se útil para indicar alterações nas funções anabólicas normais que ocorrem durante o sono, induzidas pelo exercício realizado durante o dia $^{70}$.

Contudo, exercícios demasiadamente intensos e de longa duração podem levar a um período inadequado de recuperação. Existem evidências de que a síndrome de overtraining manifesta-se, além de outros parâmetros fisiológicos, também no padrão de sono ${ }^{71}$.

Um sono de boa qualidade é fundamental para a restauração física e mental. No caso dos exercícios, entretanto, existe uma relação em forma de "U" invertido entre a fadiga induzida pelo exercício e a qualidade do sono $^{47}$ (fig. 1).

Portanto, é possível dizer que o exercício em demasia, assim como um sono de má qualidade (quer seja por perturbação pelo exercício, quer seja por outros distúrbios), pode prejudicar o rendimento durante os treinamentos ou mesmo durante provas importantes.

Conhecer melhor o padrão de sono pode ser uma referência importante para se alcançar um melhor desempenho na realização de exercícios, bem como para inferir o nível de estresse do treinamento, uma vez que alterações nestes padrões podem decorrer de um treinamento excessivo.

Outro fator importante a ser considerado é a presença de distúrbios de sono como apnéia, insônia, bruxismo ou movimentos periódicos de pernas que, por interferirem na qualidade do sono, podem comprometer o desempenho esportivo, prejudicando principalmente o período de recuperação. Nestes casos devem-se tomar atitudes de higiene do sono e, em casos mais complexos, procurar um médico especialista na área para a verificação do padrão de sono através de uma polissonografia. 


\section{REFERÊNCIAS}

1. Krueger JA, Jr. Obál F, Fang J. Why we sleep: a theoretical view of sleep function. Sleep Med Rev 1999;3:119-29.

2. Lyznicki JM, Doege TC, Davis RM, Williams MA. Sleepiness, driving, and motor vehicle crashes. JAMA 1998;279:1908-13.

3. Eberhart R, Hu X, Foresman BH. Dangers of sleepiness and inattention while driving. J Am Osteopath Assoc 2000;100(Suppl 8):9-14.

4. Ohayon MM, Caulet M, Philip P, Guilleminaut C, Priest RG. How sleep and mental disorders are related to complaints of daytime sleepiness. Arch Intern Med 1997;157:2645-52.

5. Leger D. Public health and insomnia: economic impact. Sleep 2000;23 (Suppl 3):69-76.

6. Heinzelmann F, Bagley R. Response to physical activity programs and their effects on health behavior. Public Health Rep 1970;85:905-11.

7. McCarthy ME, Waters WF. Decreased attentional responsivity during sleep deprivation: orienting response latency, amplitude, and habituation. Sleep 1997;20:115-23.

8. Philip P, Taillard J, Quera-Salva MA, Bioulac B, Årkestedt T. Simple reaction time, duration of driving and sleep deprivation in young versus old automobile drivers. J Sleep Res 1999;8:9-14.

9. Wimmer F, Hoffmann RF, Bonato RA, Moffitt AR. The effects of sleep deprivation on divergent thinking and attention process. J Sleep Res 1992; 1:223-30.

10. Harrison Y, Horne JA. Sleep loss and temporal memory. Q J Exp Psychol A 2000;53:271-9.

11. Mello MT, Santana MG, Souza LM, Oliveira PCS, Ventura ML, Stampi C, et al. Sleep patterns and sleep-related complaints of Brazilian interstate bus drivers. Braz J Med Biol Res 2000;33:71-7.

12. Spiegel K, Leproult R, van Cauter E. Impact of sleep debt on metabolic and endocrine function. Lancet 1999;354:1435-39.

13. Brouwers FM, Lenders JW. Sleep-disordered breathing and hypertension. N Engl J Med 2000;343:967.

14. Lavie P. The enchanted world of sleep. New Haven: Yale University Press, 1996.

15. Chokroverty S. Sleep disorders medicine: basic science, technical considerations, and clinical aspects. Washington: Butterworth-Heinemann, 1994.

16. Tononi G, Cirelli C. The frontiers of sleep. Trends in neurosciences 1999;22:417-8.

17. Rechastchaffen A. Current perspectives on the function of sleep. Perspect Biol Med 1998;41:359-90.

18. Buela G. Avaliação dos distúrbios de iniciar e manter o sono. In: Reimão R. Sono: aspectos atuais. Rio de Janeiro: Atheneu Editora, 1990: 33.

19. Baker TL. Introduction to sleep and disorders. Med Clin North Am 1985; 69:1123-52.

20. Kleitman N. Sleep and wakefulness. London: Midway Reprint, 1987.

21. Timo-Iaria C. Evolução histórica do estudo do sono. In: Tufik S. Sono: aspectos básicos. São Paulo: Instituto do Sono-Unifesp, 2000:1-25.

22. Rechstchaffen A, Kales A. A manual of standardized terminology, techniques, and scoring system for sleep stages of human subjects. Washington: U.S. Government Printing office, 1968.

23. Carskadon MA, Rechstchaffen A. Monitoring and staging human sleep. In: Kryger MH, Roth T, Dement WC. Principles and practice of sleep medicine. $3^{\text {rd }}$ ed. Philadelphia: WB Saunders Co., 2000.

24. Pinto Júnior LR. Polissonografia normal e nos principais distúrbios do sono. In: Tufik S. Sono: aspectos clínicos. São Paulo, Instituto do SonoUnifesp, 2000:1-26.
25. Hobson JA. Neural control of sleep. In: Turek FW, Zee PC. Regulation of sleep and circadian rhythms. New York: Marcel Dekker, Inc., 1999: 81-110.

26. Roth T, Roehrs T. Sleep organization and regulation. Neurology 2000; 54:S2-S7.

27. Davis FC, Frank MG, Heller HC. Ontogeny of sleep and circadian rhythms. In: Turek FW, Zee PC. Regulation of sleep and circadian rhythms. New York: Marcel Dekker, Inc., 1999:19-79.

28. Gronfier C, Simon C, Piquard F, Ehrhart J, Brandenberger G. Neuroendocrine processes underlying ultradian sleep regulation in man. J Clin Endocrinol Metabol 1999;84:2686-90.

29. Borbély AA, Acherman P. Sleep homeostatic and models of sleep regulation. In: Kryger MH, Roth T, Dement WC. Principles and practice of sleep medicine. $3^{\text {rd }}$ ed. Philadelphia: WB Saunders Co., 2000:377-90.

30. Williams HL, Hammack JT, Daly RL, Dement WC, Lubin A. Responses to auditory stimulation, sleep loss and the EEG stages of sleep. Electroencephalogr Clin Neurophysiol 1964;16:269-79.

31. Bes FW, Jobert M, Müller LC, Schulz H. The diurnal distribution of sleep propensity: experimental data about the interaction of the propensities for slow-wave sleep and REM sleep. J Sleep Res 1996;5:90-8.

32. Cirelli C, Tononi G. Differences in gene expression between sleep and waking as revealed by mRNA differential display. Brain Res Mol Brain Res 1998;56:293-305.

33. Franken P, Malafosse A, Tafti M. Genetic determinants of sleep regulation in inbred mice. Sleep 1999;22:155-69.

34. Moore RY. Circadian rhythms: basic neurobiology and clinical applications. Annu Rev Med 1997;48:253-66.

35. LeSauter J, Silver R. Output signals of the SCN. Chronobiol Int 1998; 15:535-50.

36. Velluti R. Fisiologia do sono. In: Reimão R. Sono: aspectos atuais. Rio de Janeiro: Atheneu Editora, 1990:1-16.

37. Driver HS, Taylor S. Exercise and sleep. Sleep Med Rev 2000;4:387402.

38. Hobson JA. Sleep after exercise. Science 1968;162:1503-5.

39. Horne JA, Moore VJ. Sleep EEG effects of exercise with and without additional body cooling. Electroencephalogr Clin Neurophysiol 1985; 60:33-8.

40. Murphy PJ, Campbell SS. Nighttime drop in body temperature: a physiological trigger for sleep onset? Sleep 1997;20:505-11.

41. Lu J, Greco MA, Shiromani P, Saper CB. Effect of lesions of the ventrolateral preoptic nucleus on NREM and REM sleep. J Neurosci 2000;20: 3830-42.

42. Maquet P. Sleep function(s) and cerebral metabolism. Behav Brain Res 1995;69:75-83.

43. Mamelak M. Neurodegeneration, sleep, and cerebral energy metabolism: a testable hypothesis. J Geriatr Psychiatry Neurol 1997;10:29-32.

44. Chervin RD. Sleepiness, fatigue, tiredness, and lack of energy in obstructive sleep apnea. Chest 2000;118:372-9.

45. Montgomery I, Trinder J, Paxton SJ. Energy expenditure and total sleep time: effect of physical exercise. Sleep 1982;5:159-68.

46. Berger RJ, Phillips NH. Energy conservation and sleep. Behav Brain Res 1995;69:65-73.

47. Hobson JA. Sleep after exercise. Science 1968;162:1503-5.

48. Baekeland F, Lasky R. Exercise and sleep patterns in college athletes Percep Mot Skills 1966;23:1203-7. 
49. Youngstedt SD, O'Connor PJ, Crabbe JB, Dishman RK. The influence of acute exercise on sleep following high caffeine intake. Physiol Behav 2000;68:563-70.

50. Matsumoto J, Nishisho T, Suto T, Sadahiro T, Miyoshi M. Influence of fatigue on sleep. Nature 1968;218:177-8.

51. Youngstedt SD, O'Connor PJ, Dishman RK. The effects of acute exercise on sleep: a quantitative synthesis. Sleep 1997;20:203-14.

52. Driver HS, Taylor SR. Exercise and sleep. Sleep Med Rev 2000;4:387402.

53. Driver HS, Rogers GG, Mitchell D, Borrow SJ, Allen M, Luus HG, et al. Prolonged endurance exercise and sleep disruption. Med Sci Sports Exerc 1994;26:903-7.

54. Horne JA, Porter JM. Exercise and human sleep. Nature 1975;256:5735.

55. Sasazawa Y, Kawada T, Kiryu Y. Effect of daytime exercise on sleep EEG and subjective sleep. J Sound Vibration 1997;205:393-403.

56. Youngstedt SD, Kripke DF, Elliott JA. Is sleep disturbed by vigorous late-night exercise? Med Sci Sports Exerc 1999;31:864-9.

57. Edgar D, Dement WC. Regularly scheduled voluntary exercise synchronizes the mouse circadian clock. Am J Physiol 1991;261:r928-33.

58. Marchant EG, Mistlberger RE. Entrainment and phase shifting of circadian rhythms in mice by forced treadmill running. Physiol Behav 1996; 60:657-63.

59. Marchant EG, Watson NV, Mistlberger RE. Both neuropeptide $Y$ and serotonin are necessary for entrainment of circadian rhythms in mice by treadmill running schedules. J Neurosci 1997;17:7974-87.

60. Eastman CI, Hoese EK, Youngstedt SD, Liu L. Phase-shifting human circadian rhythms with exercise during the night shift. Physiol Behav 1995;58:1287-91.
61. Van Reeth O, Sturis J, Byrne MM, Blackman JD, L'Hermite-Balériaus M, Leproult R, et al. Nocturnal exercise phase delays circadian rhythms of melatonin and thyrotropin secretion in normal men. Am J Physiol 1994;266:E964-74.

62. Buxton OM, Frank SA, L'Hermite-Balériaus M, Leproult R, Turek FW, van Cauter E. Role of intensity and duration of nocturnal exercise in causing phase delays of human circadian rhythms. Am J Physiol 1997; 237:r536-42.

63. Shapiro CM, Griesel RD, Bartel PR, Jooste PL. Sleep patterns after graded exercise. J Appl Physiol 1975;39:187-90.

64. Guilleminault C, Clerk A, Black J, Labanowski M, Pelayo R, Claman D. Ann Intern Med 1995;155:838-44.

65. Van Reeth O. Sleep and circadian disturbance in shift work: strategies for their management. Horm Res 1998;49:158-62.

66. Mello MT, Fernandez AC, Tufik S. Levantamento epidemiológico da prática de atividade física na cidade de São Paulo. Rev Bras Med Esporte 2000;6:119-24.

67. Van Cauter E, Copinschi G. Interaction between sleep and the somatotropic axis. Sleep 1998;21:553-66.

68. Adam K, Oswald, I. Protein synthesis, bodily renewal and the sleepwake cycle. Clin Sci (Colch) 1983;65:561-7.

69. Horne JA. Human sleep and tissue restitution: some qualifications and doubts. Clin Sci (Colch) 1983;65:569-78.

70. Kern W, Perras B, Wodick R, Fehm HL. Hormonal secretion during nighttime sleep indicating stress of daytime exercise. J Appl Physiol 1995; 79:1461-8.

71. Budgett R. Overtraining syndrome. Br J Sports Med 1990;24:231-6.

Bolsa de Pesquisa: CAPES. 